\title{
The Effects of Interrupting Prolonged Sitting With Frequent Bouts of Light-Intensity Standing Exercises on Blood Pressure in Stroke Survivors: A Dose Escalation Trial
}

\author{
Paul Mackie, Gary Crowfoot, Heidi Janssen, Elizabeth Holliday, David Dunstan, and Coralie English
}

\begin{abstract}
Background: Interrupting prolonged sitting acutely lowers blood pressure in nonstroke populations. However, the dose-response effect in stroke survivors is unknown. The authors investigated different doses of light-intensity standing exercises that interrupt prolonged sitting and reduce blood pressure immediately and over 24 hours in stroke survivors. Methods: Within-participant, laboratory-based, dose escalation trial. Conditions $(8 \mathrm{~h})$ were prolonged sitting and 2 experimental conditions of standing exercises with increasing frequency ( 3 cohorts, $2 \times 5 \mathrm{~min}$ to $6 \times 5 \mathrm{~min}$ ). The primary outcome is the mean systolic blood pressure. Results: Twenty-nine stroke survivors (aged 66 [12] y) participated. Frequent bouts of standing exercises lowered the mean systolic blood pressure following the $4 \times 5$-minute $(-2.1 \mathrm{~mm} \mathrm{Hg} ; 95 \%$ confidence interval [CI], -3.6 to -0.6$)$ and $6 \times 5$-minute conditions $(-2.3 \mathrm{~mm} \mathrm{Hg} ; 95 \% \mathrm{CI},-4.2$ to -0.5$)$ compared with prolonged sitting. Diastolic blood pressure was lowered following the $6 \times 5-$ minute condition $(-1.4 \mathrm{~mm} \mathrm{Hg} ; 95 \% \mathrm{CI},-2.7$ to -0.2$)$. The 24 -hour systolic blood pressure increased following the $2 \times 5$-minute condition (6.9 mm Hg; 95\% CI, 3.1 to 10.6). Conclusions: Interrupting prolonged sitting with more frequent bouts of standing exercises lowers systolic and diastolic blood pressure in stroke survivors. However, reductions may only be short term, and investigations on sustained effects are warranted.
\end{abstract}

Keywords: exercise, hypertension, secondary prevention

Hypertension is the leading risk factor for first and recurrent stroke, ${ }^{1,2}$ and approximately 1.4 billion people worldwide were living with hypertension in $2010 .^{3}$ Lifestyle interventions involving exercise as a primary component form an integral part of blood pressure management, alongside pharmacological therapies. ${ }^{4}$ However, it is well established that stroke survivors engage in low levels of physical activity ${ }^{5-7}$ and spend large portions of the day sitting. ${ }^{8-10}$ Stroke survivors spend, on average, $22 \%$ more time sitting during waking hours than healthy age-matched controls. ${ }^{11}$ This increases the risk of recurrent strokes and other adverse events in the already compromised health of stroke survivors.

Long bouts of prolonged sitting during waking hours are associated with elevated blood pressure. ${ }^{12,13}$ Interrupting prolonged periods of sitting with frequent bouts of physical activity or standing have acute beneficial effects on various measures of cardiometabolic health, including blood pressure. ${ }^{14-17}$ In overweight or obese persons, ${ }^{17}$ or those with type 2 diabetes, ${ }^{16}$ mean reductions of 2 to $16 \mathrm{~mm} \mathrm{Hg}$ in systolic blood pressure and 2 to $10 \mathrm{~mm} \mathrm{Hg}$ in diastolic blood pressure have been reported

Mackie, Janssen, and English are with the School of Health Sciences and Priority Research Centre for Stroke and Brain Injury, The University of Newcastle, Newcastle, NSW, Australia. Mackie, Crowfoot, Janssen, and English are with the Centre for Research Excellence in Stroke Recovery and Rehabilitation, The Florey Institute of Neuroscience, Melbourne, VIC, Australia. Crowfoot is also with the School of Nursing and Midwifery and Priority Research Centre for Stroke and Brain Injury, The University of Newcastle, Newcastle, NSW, Australia. Janssen is also with the Hunter Stroke Service, Hunter New England Local Health District, Newcastle, NSW, Australia. Holliday is with the School of Medicine and Public Health University of Newcastle, Newcastle, NSW, Australia. Dunstan is with the Baker Heart and Diabetes Institute, Melbourne, VIC, Australia; and the Mary MacKillop Institute for Health Research, Australian Catholic University, Melbourne, VIC, Australia. Mackie (mackiep6@hotmail.com) is corresponding author. following frequent (every $30 \mathrm{~min}$ ) bouts $(2-3 \mathrm{~min})$ of light- to moderate-intensity simple resistance activities (calf raises, knees raises, gluteal contractions, and mini squats) or walking.

Preliminary evidence in stroke survivors indicates that breaking up prolonged sitting with 3 minutes (every $30 \mathrm{~min}$ ) of light-intensity exercises undertaken while standing (STANDEX; calf raises, mini squats, and marching on the spot) reduces mean systolic blood pressure by $3.5 \mathrm{~mm} \mathrm{Hg} .{ }^{18,19}$ However, in the trial by English et al, ${ }^{18,19}$ blood pressure was a secondary outcome, and measures were not blinded. In people who are overweight or obese, the beneficial effects on blood pressure following frequent short bouts $(2.5 \mathrm{~h}$ total accumulated time, completed as $2 \times 10 \mathrm{~min}, 2 \times 15 \mathrm{~min}, 2 \times 20 \mathrm{~min}$, and $2 \times 30 \mathrm{~min}$ bouts) of static standing or cycling are sustained for 3 hours postintervention. ${ }^{20}$ However, it is unknown if more frequent bouts of STAND-EX have greater benefits on blood pressure compared with less frequent bouts in stroke survivors during and immediately following the prescribed interventions. Therefore, further well-controlled trials are needed to investigate the physiological effects of frequent interruptions in prolonged sitting in stroke survivors.

There is extensive evidence on the benefits of interrupting prolonged sitting time on biomarkers of cardiometabolic health in various populations. ${ }^{14,15}$ However, evidence for the effects in people with stroke, and on the dose-response effect, is lacking. The aim of this study was to investigate different doses of interruptions involving standing exercises (STAND-EX) during 8 hours of prolonged sitting in stroke survivors. The specific research questions were

1. Are more frequent bouts of STAND-EX superior to less frequent bouts in reducing blood pressure acutely and over 24 hours?

2. Are increasing bouts of STAND-EX safe and feasible? 


\section{Method}

\section{Design}

A laboratory-based dose escalation trial was conducted at the Hunter Medical Research Institute (NSW, Australia; Figure 1 and Tables 1 and 2). Stroke survivors were recruited from the Hunter and Newcastle region via the Hunter Stroke Research Volunteer Register. In cohorts of 10 participants at a time, the participants first attended a familiarization session, followed by three 8-hour conditions. These 3 conditions were composed of a control condition ( $8 \mathrm{~h}$ of prolonged sitting) and 2 experimental conditions until a dose limiting threshold was achieved. The published trial protocol ${ }^{21}$ details the dose escalation procedure that was to be undertaken. In brief, Cohort 1 would undertake experimental condition 1 ( $8 \mathrm{~h}$ of sitting interrupted by $2 \times 5 \mathrm{~min}$ bouts of STAND-EX) followed by experimental condition 2 ( $8 \mathrm{~h}$ of sitting interrupted by $4 \times 5 \mathrm{~min}$ bouts of STAND-EX). Cohort 2 would undertake experimental condition 2 followed by experimental condition 3 ( $8 \mathrm{~h}$ of sitting interrupted by $6 \times 5 \mathrm{~min}$ bouts of STAND-EX). If the dose limiting threshold (detailed in the published protocol ${ }^{21}$ ) was attained, a final cohort would repeat the penultimate cohort. However, this study details the modified protocol that was completed due to the COVID-19 pandemic (2020). As outlined in Table 1, Cohort 1 undertook experimental condition 1 ( $8 \mathrm{~h}$ of sitting interrupted by $2 \times 5 \mathrm{~min}$ bouts of STAND-EX) followed by experimental condition 2 ( $8 \mathrm{~h}$ of sitting interrupted by $4 \times 5$ min bouts of STAND-EX). Cohort 2 undertook experimental condition 2 followed by experimental condition 3 ( $8 \mathrm{~h}$ of sitting interrupted by $6 \times 5$ min bouts of STAND-EX). The final cohort (Cohort 3 ) undertook experimental condition 2 followed by experimental condition 3 ( $8 \mathrm{~h}$ of sitting interrupted by $6 \times 5 \mathrm{~min}$ bouts of STAND-EX) to confirm that the optimal tolerable amount of STAND-EX had been achieved. Each condition was separated by a minimum 4-day washout period. Nonrandomization of groups was a deliberate strategy in order to carefully test the safety, feasibility, and effect of an increasing "dose" of STAND-EX bouts in accordance with the dose escalation design. The trial was approved by the Hunter New England Research Ethics Committee $(17 / 06 / 21 / 4.04)$ and the University of Newcastle's Human Research Committee (H-2017-0296), and registered with the Australian New Zealand Clinical Trials Registry (ACTRN126170015 17369). The participants provided verbal and written informed consent prior to data collection. This study reports results for the primary outcome (systolic blood pressure) collected during and for 24 hours following the 8-hour control condition (prolonged sitting). In addition, safety and feasibility outcomes of STAND-EX bouts are reported.

\section{Participants}

Stroke survivors were included if they (1) were $>3$ months poststroke, (2) could stand up from a sitting position, (3) had a walking speed $\geq 0.4 \mathrm{~m} / \mathrm{s}$, (4) could ambulate on level surfaces (Functional Ambulation Classification $\geq 3$ ), (5) were $\geq 18$ years of age, and (6) spent $\geq 7$ hours of self-reported sitting during waking hours. Stroke survivors were excluded if they (1) engaged in $\geq 150$ minutes of self-reported moderate- to vigorous-intensity physical activity

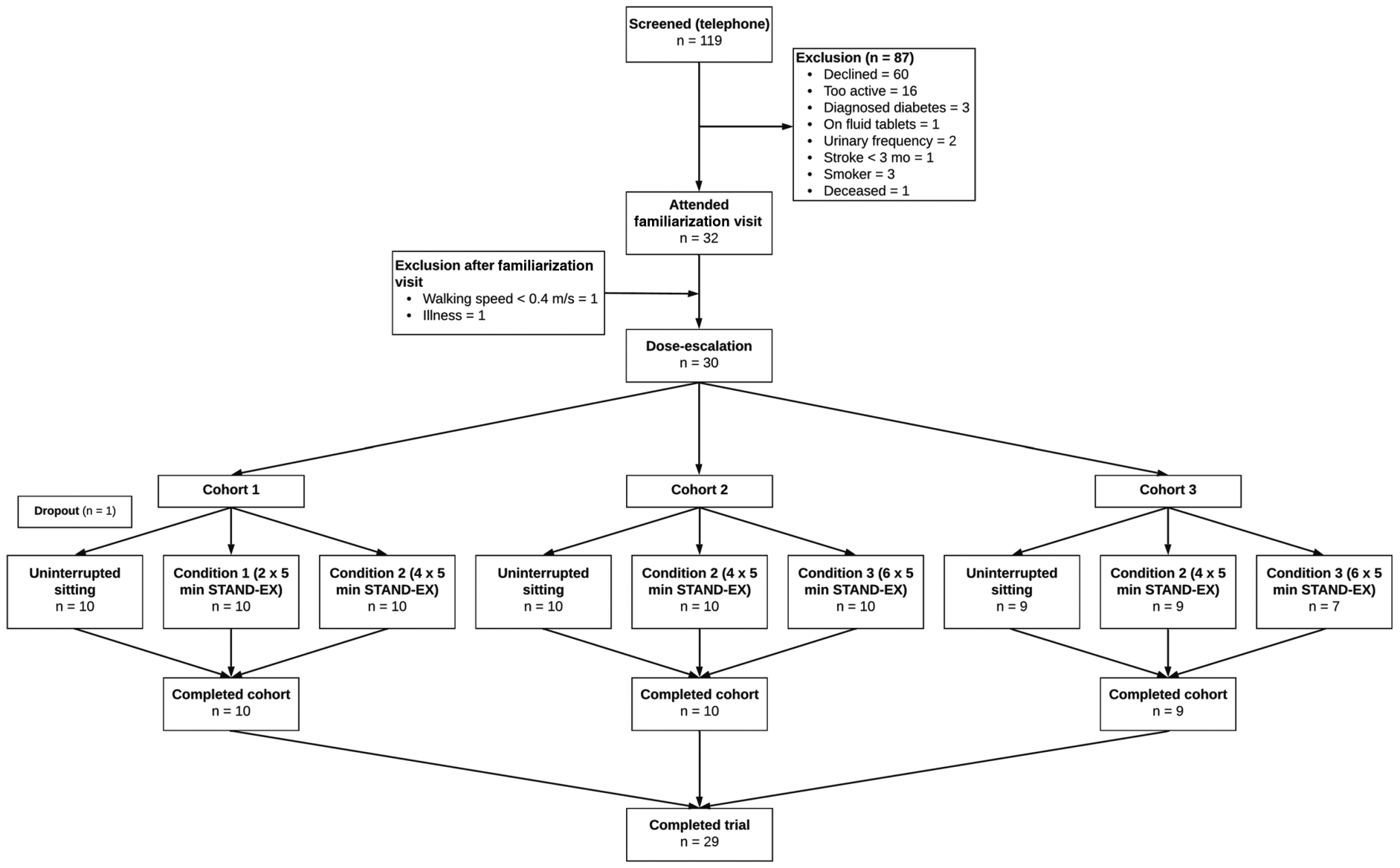

Figure 1 - Flow of participants. STAND-EX indicates light-intensity exercises while standing (calf raises, mini squats, and marching on the spot). 
Table 1 Experimental Conditions by Cohort

\begin{tabular}{lccc}
\hline & $\begin{array}{c}\text { Sitting } \\
(8 \mathrm{~h})\end{array}$ & $\begin{array}{c}\text { Experiment condition 1 } \\
(2 \times 5 \mathrm{~min})\end{array}$ & $\begin{array}{c}\text { Experiment condition 2 } \\
(4 \times 5 \mathrm{~min})\end{array}$ \\
\hline Cohort 1 & $\begin{array}{c}\text { Experiment condition 3 } \\
(6 \times 5 \mathrm{~min})\end{array}$ \\
Cohort 2 & & &
\end{tabular}

per week, (2) had urinary urgency, (3) were diagnosed with diabetes or took diabetes medication (other than metformin), (4) had a body mass index $>45 \mathrm{~kg} / \mathrm{m}^{2}$, (5) were pregnant, (6) were diagnosed with a condition that limited their ability to complete the exercises prescribed, or (7) were a smoker.

The following baseline characteristics were collected at an initial familiarization visit: dietary intake (24-h recall method measured by a qualified dietitian), risk of type 2 diabetes mellitus (AUSDRISK assessment tool ${ }^{22}$ ), stroke severity and type (National Institute of Health Stroke Scale, ${ }^{23}$ Oxfordshire classification $\left.{ }^{24}\right)$, fatigue (Fatigue Assessment Scale ${ }^{25}$ ), and walking ability (10-m walk test and Functional Ambulation Classification). Resting blood pressure was collected using an automated blood pressure monitor (Connex 6700 vital signs monitor; Welch Allyn Inc, NY) and was averaged over 3 measures (each separated by $1 \mathrm{~min}$ ) following a 5-minute seated rest period. All blood pressure measures were taken in an upright seated position on the nonparetic limb. Time spent in physical activity and sitting/lying was measured using the activPAL3 activity monitor (activPAL3; PAL Technologies Ltd, Glasgow, Scotland). The activPAL3 monitor was positioned on the nonparetic limb and recorded physical activity and sedentary behavior levels for 24 hours per day for a minimum of 3 days prior to and post experimental conditions. Monitor wear time during waking hours was processed using validated algorithms from the ProcessingPAL software (version 1.3; ProcessingPAL, Leicester, UK). An invalid day was determined from the following criteria: (1) $>95 \%$ of the day spent in an activity, (2) limited monitor wear time during waking hours $(<10 \mathrm{~h}),{ }^{26}$ or $(3)$ limited steps taken $(<100$ steps $)$

\section{Experimental Condition}

Cohorts of participants completed a control condition ( $8 \mathrm{~h}$ prolonged sitting), followed by 2 experimental conditions. During the 24 hours prior to each day of data collection, the participants followed a prescribed meal plan, including a standardized evening meal. The energy requirements for individual meal plans were estimated using the Schofield equation for approximating the basal metabolic rate, ${ }^{27}$ taking into account age, weight, and suitable physical activity level (sedentary adult's equivalent to 1.3). For the 48 hours prior to each day of data collection, the participants were instructed to refrain from caffeine, alcohol, and engaging in moderate to vigorous physical activity.

The participants arrived at the Hunter Medical Research Institute at 07:30 after a 12-hour fast and were fitted with an ambulatory blood pressure monitor. A standardized breakfast was consumed from 08:30 to 09:00, and the trial commenced at 09:00. The participants were supervised and instructed to remain seated, only rising to void or complete the prescribed dose of STAND-EX. Bouts of STAND-EX were 5 minutes in duration and consisted of the following exercises: 20 seconds of calf raises, 20 seconds of mini squats, 20 seconds of marching on the spot, and each repeated 5 times at BORG $\leq 3$ (Table 2). The participants were allowed reading materials and computers, and they were provided with a selection of DVDs to watch. Potentially stimulating activities that could influence blood pressure, such as horror movies, were avoided. Lunch was consumed from 12:30 to 13:00. The macronutrient profile target for combined meals was $16 \%$ of protein, $20 \%$ of fat, and $61 \%$ of carbohydrate. Each meal was composed of approximately $33 \%$ of the participant's estimated daily requirements. The volume of water consumed during the control condition was recorded and maintained across experimental conditions. Toilet breaks were timed and noted. The participants took their medication as prescribed. The 8-hour experimental day ceased at 4:00 p.m.

\section{Outcome Measures}

The primary outcome was the mean systolic blood pressure, measured during and for 24 hours following the 8-hour experimental condition using an ambulatory blood pressure monitor (ABPM 7100; Welch Allyn Inc). Blood pressure measurements were automatically recorded every 30 minutes, prior to standardized meals and bouts of STAND-EX. On completion of the 8 hours of sitting, at 16:00, continuous blood pressure was measured every 60 minutes for the next 24 hours $\left(16: 00-16: 00^{+1}\right.$ day $)$. The participants were asked to remain still during measurements and to remove the ambulatory blood pressure monitor when showering and at night when sleeping. The participants and researchers were blinded to blood pressure measurements since the blood pressure monitor did not display readings until downloaded.

The feasibility of undertaking the STAND-EX bouts during the experimental conditions was measured as perceived exertion using the Borg Scale of rate of perceived exertion ( $0-10$ scale; $0=$ no exertion), ${ }^{28}$ fatigue using a visual analogue scale (0-10 scale; $0=$ not fatigued), perceived difficulty using a visual analogue scale (0-10 scale; $0=$ not difficult), intensity of exercise using percentage of maximum heart rate measured by a pulse oximeter (every $30 \mathrm{~min}$ and immediately after bouts of STAND-EX), and adherence as time spent exercising. The safety of the STAND-EX bouts and conditions was measured as the number of adverse events, including pain or falls. 


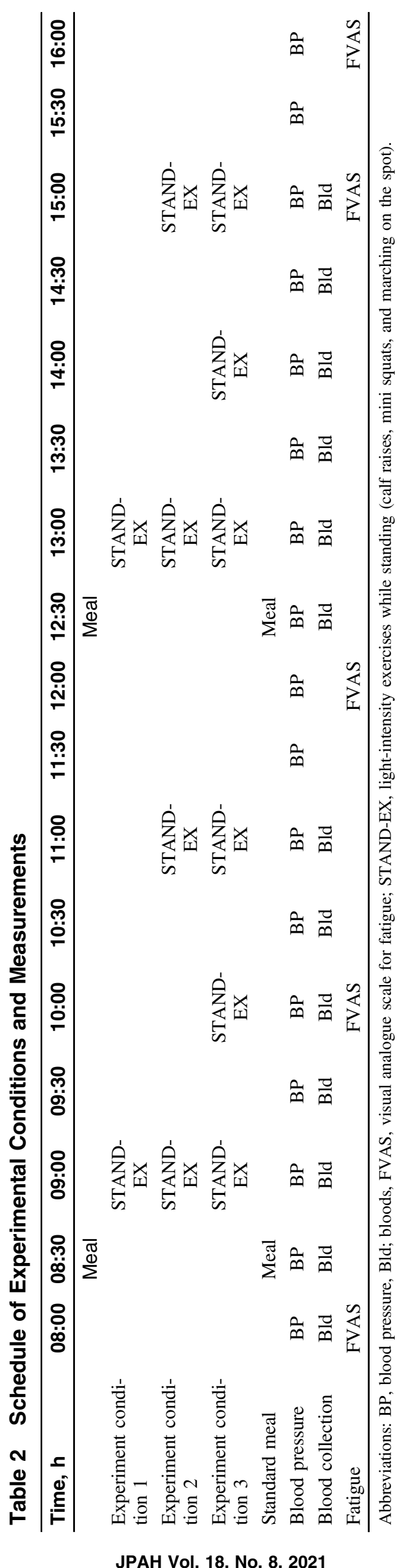

JPAH Vol. 18, No. 8, 2021 


\section{Data Analysis}

Power calculations were conducted a priori and reported in the published protocol paper $^{21}$; these determined that $\mathrm{n}=30(\mathrm{n}=10 /$ cohort) would provide sufficient power (80\%) to detect a withinperson, between-condition difference in systolic blood pressure of $3.5 \mathrm{~mm} \mathrm{Hg}$ (assumed SD $15 \mathrm{~mm} \mathrm{Hg}$ ) at the most beneficial dose of STAND-EX. Blood pressure collected during experimental conditions (08:00-16:00) and 24 hours post $\left(16: 00-16: 00^{+1}\right.$ day $)$ was analyzed separately. The 24-hour postexperimental blood pressure data were analyzed between 16:00 and 21:00 (evening) on the day of the experimental conditions and between 10:00 and 16:00 on the day after the experimental conditions. Analyses followed the intention-to-treat principle.

Linear mixed models, including fixed effects (condition and time) and random intercepts (accounting for repeated measures on participants), were used to analyze between-condition differences in systolic and diastolic blood pressure (during and $24 \mathrm{~h}$ postexperimental conditions). Secondary analysis examined the between-condition effects of participants on and not on antihypertensive medication on systolic and diastolic blood pressure during experimental conditions. Linear mixed models use all available data and provide unbiased effect estimates, assuming the data are missing at random. A separate analysis of feasibility examined the between-condition differences in resting heart rate (averaged across a day), fatigue (averaged across a day), and degree of difficulty (end of day). In addition, within-person, between-condition differences in pre- and post-STAND-EX bouts for heart rate and Borg ratings of perceived exertion were analyzed. The safety of STAND-EX bouts was described as the number of adverse events. Due to the small sample size of the trial, the statistical threshold was set at $5 \%$ $(P<.05)$ for all analyses. The data are represented as mean (SD) unless otherwise stated.

\section{Results}

\section{Participants}

Thirty-two participants attended the Hunter Medical Research Institute between November 2017 and March 2020. We were unable to complete all 5 cohorts as planned (Figure 1, Table 2). Overall, 29 participants completed the trial and were included in the analyses (Figure 1). The onset of the COVID-19 global pandemic (2020) prevented 2 participants from completing their final visit $(6 \times 5$ min condition) and prevented recruitment of the final participant needed to reach the target sample size. However, due to funding restrictions and low recruitment rates $(27 \%$ of potential participants contacted were eligible), the dose-limiting threshold was not obtained, and only 3 experimental conditions were tested $(2 \times 5 \mathrm{~min}, 4 \times 5 \mathrm{~min}$, and $6 \times 5 \mathrm{~min})$. Therefore, to reach sufficient power $(n=30)$ as determined in the published protocol paper, the $4 \times 5$ - and $6 \times 5$-minute conditions were repeated (Figure 1).

The participants' mean age was 66 (12) years, with $16(60 \%)$ participants classified as having had a minor stroke (National Institute of Health Stroke Scale score 1-4) and 15 (52\%) with left-side hemiparesis. The participants were, on average, 80 (94) months poststroke. At familiarization, $18(62 \%)$ participants had a systolic blood pressure $>130 \mathrm{~mm} \mathrm{Hg}, 12(41 \%)$ participants had a diastolic blood pressure $>80 \mathrm{~mm} \mathrm{Hg}$, and 17 (59\%) participants were on antihypertensive medication. Table 3 details the participant characteristics. The participants spent, on average, 10.5 (2.9) hours per day sitting, 3.4 (1.8) hours per day standing, and 1.2 (0.6)
Table 3 Characteristics of Participants

\begin{tabular}{|c|c|}
\hline Characteristics & $\mathrm{n}=\mathbf{2 9}$ \\
\hline Age, $y$, mean (SD) & $66(12)$ \\
\hline Sex, number male, $\%$ & $15(52)$ \\
\hline Weight, kg, mean (SD) & $88(20)$ \\
\hline Height, m, mean (SD) & $\begin{array}{c}1.68 \\
(0.09)\end{array}$ \\
\hline BMI, $\mathrm{kg} / \mathrm{m}^{2}$, mean (SD) & $31.2(6.4)$ \\
\hline Waist circumference, $\mathrm{cm}$, mean (SD) & $104(16)$ \\
\hline Time since stroke, mo, mean (SD) & $80(94)$ \\
\hline Systolic blood pressure, mm Hg, mean (SD) & $137(17)$ \\
\hline Diastolic blood pressure, $\mathrm{mm} \mathrm{Hg}$, mean (SD) & $79(7)$ \\
\hline AUSDRISK, mean (SD) & $16(4)$ \\
\hline \multicolumn{2}{|l|}{ Medications, number yes, $\%$} \\
\hline Anticoagulants & $20(69)$ \\
\hline Antidepressants & $5(17)$ \\
\hline Cholesterol lowering & $16(55)$ \\
\hline Antihypertensive & $17(59)$ \\
\hline ACE inhibitors & $8(28)$ \\
\hline ARBs & $2(7)$ \\
\hline Calcium channel blocker & $5(17)$ \\
\hline Beta blocker & $8(28)$ \\
\hline Thiazide diuretic & $1(3)$ \\
\hline Walking aid, number yes (\%) & $7(24)$ \\
\hline Walking speed, $\mathrm{m} / \mathrm{s}$, mean (SD) & $1.0(0.3)$ \\
\hline Walk on admission to hospital, number yes (\%) & $9(32)$ \\
\hline Functional Ambulation Classification, mean (SD) & $5(0)$ \\
\hline Living arrangement, with spouse or family, number yes (\%) & $25(86)$ \\
\hline NIHSS, mean (SD) & $3.1(3.7)$ \\
\hline No symptoms (score 0 ), number yes $(\%)$ & $5(18)$ \\
\hline Minor (scores $1-4)$, number yes $(\%)$ & $16(60)$ \\
\hline Moderate (scores 5-15), number yes (\%) & $7(27)$ \\
\hline \multicolumn{2}{|l|}{ Oxfordshire classification categories, number (\%) } \\
\hline TACI & $2(7)$ \\
\hline PACI & $11(41)$ \\
\hline Lacunar & $2(7)$ \\
\hline POCI & $1(4)$ \\
\hline Hemorrhage & $11(41)$ \\
\hline Side of hemiparesis, number left $(\%)$ & $15(52)$ \\
\hline No hemiparesis, number yes (\%) & $1(3)$ \\
\hline Fatigue Assessment Scale (scores 10-50), mean (SD) & $23(7)$ \\
\hline
\end{tabular}

Abbreviations: ACE, angiotensin-converting-enzyme; ARBs, angiotensin II receptor antagonist; AUSDRISK, Australian type 2 diabetes risk assessment tool; BMI, body mass index; TACI, total anterior circulation infarct; NIHSS, National Institute of Health Stroke Scale; PACI, partial anterior circulation infarct; POCI, posterior circulation infarct.

hours per day walking for the minimum 4 days prior to completing their first experimental condition. The participants were slightly more active on the days after the experimental conditions (see Supplementary Table S1 [available online]), although these differences were small. For example, the participants spent 0.5 hours more per day standing (95\% confidence interval [CI], 0.1 to 0.9 ) in the days following the $6 \times 5$-minute condition compared with the 4 days prior to completing their first experimental condition. 


\section{Effect of STAND-EX Bouts on Immediate and 24-Hour Blood Pressure}

Table 4 details the between-condition differences in systolic and diastolic blood pressure during and over the 24 hours after the experimental conditions. Overall, $14(<1 \%)$ blood pressure readings were missing during the experimental conditions $(n=29)$, and $381(34 \%)$ blood pressure readings were missing during the 24 hours post experimental conditions $(n=29)$. During the 24 hours post experimental conditions, 147 (29\%) blood pressure readings were missing during the evening (16:00-21:00), and 234 (39\%) blood pressure readings were missing the day after (10:00-16:00). This includes 1 participant, who was unable to wear the ambulatory blood pressure monitor during the 24 hours post experimental conditions, due to physical impairments. Available blood pressure data from all participants were included, and analyses were adjusted for baseline differences across conditions. A sensitivity analysis was performed to test the effect of including data from 1 participant recruited despite not meeting the inclusion criteria (body mass index $>45 \mathrm{~kg} / \mathrm{m}^{2}$ ). The results were similar, so the final analyses included all participant data.

Systolic blood pressure was significantly lower during both the $4 \times 5$-minute condition $(-2.1 \mathrm{~mm} \mathrm{Hg} ; 95 \% \mathrm{CI},-3.6$ to -0.6$)$ and the $6 \times 5$-minute condition $(-2.3 \mathrm{~mm} \mathrm{Hg} ; 95 \% \mathrm{CI},-4.2$ to -0.5$)$, compared with prolonged sitting (Figure 2). Diastolic blood pressure was significantly lower following the $6 \times 5$-minute condition
( $-1.4 \mathrm{~mm} \mathrm{Hg} ; 95 \% \mathrm{CI},-2.7$ to -0.2$)$ compared with prolonged sitting (Figure 2). Twenty-four-hour postexperimental systolic blood pressure was significantly higher $(6.9 \mathrm{~mm} \mathrm{Hg} ; 95 \% \mathrm{CI}$, 3.1 to 10.6$)$ in the $2 \times 5$-minute condition compared with prolonged sitting. No significant between-condition differences for systolic blood pressure were found for the $4 \times 5$ - and $6 \times 5$-minute conditions compared with prolonged sitting. There were no significant between-condition differences in 24-hour postexperimental diastolic blood pressure in any of the experimental conditions compared with prolonged sitting. To explore whether reductions in blood pressure were maintained for at least the rest of the day after the experimental condition was finished, we examined systolic and diastolic blood pressure data for the evening period (16:00-21:00) only, but there were no significant between-condition effects.

Supplementary Table S2 (available online) details the post hoc analysis on the between-condition effects of participants on and not on antihypertensive medication on systolic and diastolic blood pressure. The participants on antihypertensive medication $(\mathrm{n}=17)$ had a significantly lower systolic blood pressure $(-3.7 \mathrm{~mm} \mathrm{Hg}$; $95 \% \mathrm{CI},-5.5$ to -2.0$)$ during the $4 \times 5$-minute condition compared with prolonged sitting. Diastolic blood pressure was also lower during both the $4 \times 5$-minute condition $(-2.6 \mathrm{~mm} \mathrm{Hg} ; 95 \% \mathrm{CI},-3.7$ to -1.4$)$ and the $6 \times 5$-minute condition $(-2.6 \mathrm{~mm} \mathrm{Hg} ; 95 \% \mathrm{CI},-4.1$ to -1.1 ) compared with prolonged sitting. In contrast, the participants not on antihypertensive medication had significantly higher

Table 4 Mean (SD) of Conditions for Systolic and Diastolic Blood Pressure (mm Hg), and Mean (95\% Cl) Difference Between Conditions

\begin{tabular}{|c|c|c|c|c|c|c|c|}
\hline \multirow[b]{2}{*}{ Outcome } & \multicolumn{4}{|c|}{ Conditions } & \multicolumn{3}{|c|}{ Difference between conditions } \\
\hline & $\begin{array}{l}\text { Sitting } \\
(n=29)\end{array}$ & $\begin{array}{c}2 \times 5 \text { min } \\
\text { condition } \\
(n=10)\end{array}$ & $\begin{array}{c}4 \times 5 \text { min } \\
\text { condition } \\
(n=29)\end{array}$ & $\begin{array}{c}6 \times 5 \text { min } \\
\text { condition } \\
(n=19)\end{array}$ & $\begin{array}{l}2 \times 5 \text { min } \\
\text { condition } \\
\text { minus } \\
\text { sitting }\end{array}$ & $\begin{array}{c}4 \times 5 \text { min } \\
\text { condition } \\
\text { minus } \\
\text { sitting }\end{array}$ & $\begin{array}{l}6 \times 5 \text { min } \\
\text { condition } \\
\text { minus } \\
\text { sitting }\end{array}$ \\
\hline \multicolumn{8}{|c|}{ Systolic blood pressure, $\mathrm{mm} \mathrm{Hg}$} \\
\hline $\begin{array}{l}\text { Experiment day } \\
(08: 00-16: 00)\end{array}$ & $\begin{array}{l}125.5 \\
(16.3)\end{array}$ & $\begin{array}{l}126.7 \\
(12.0)\end{array}$ & $\begin{array}{l}122.6 \\
(13.7)\end{array}$ & $\begin{array}{l}122.9 \\
(15.4)\end{array}$ & $\begin{array}{c}2.0 \\
(-0.2 \text { to } 4.3)\end{array}$ & $\begin{array}{c}-2.1 \\
(-3.6 \text { to }-0.6)\end{array}$ & $\begin{array}{c}-2.3 \\
(-4.2 \text { to }-0.5)\end{array}$ \\
\hline $\begin{array}{l}24 \mathrm{~h}(16: 00-21: 00, \\
10: 00-16: 00)\end{array}$ & $\begin{array}{l}126.9 \\
(16.1)\end{array}$ & $\begin{array}{l}129.9 \\
(12.8)\end{array}$ & $\begin{array}{l}126.3 \\
(16.2)\end{array}$ & $\begin{array}{l}128.0 \\
(20.5)\end{array}$ & $\begin{array}{c}6.9 \\
\text { (3.1 to } 10.6)\end{array}$ & $\begin{array}{c}1.9 \\
(-0.8 \text { to } 4.5)\end{array}$ & $\begin{array}{c}2.6 \\
(-0.8 \text { to } 5.9)\end{array}$ \\
\hline $\begin{array}{l}24 \mathrm{~h} \text {-Evening } \\
(16: 00-21: 00)\end{array}$ & $\begin{array}{l}127.3 \\
(15.3)\end{array}$ & $\begin{array}{l}130.6 \\
(13.5)\end{array}$ & $\begin{array}{l}128.1 \\
(15.0)\end{array}$ & $\begin{array}{l}129.1 \\
(20.8)\end{array}$ & $\begin{array}{c}4.6 \\
(-0.3 \text { to } 9.5)\end{array}$ & $\begin{array}{c}2.4 \\
(-1.1 \text { to } 5.9)\end{array}$ & $\begin{array}{c}4.1 \\
(-0.2 \text { to } 8.4)\end{array}$ \\
\hline $\begin{array}{l}24 \mathrm{~h}-\text { Day after } \\
(10: 00-16: 00)\end{array}$ & $\begin{array}{l}126.5 \\
(16.8)\end{array}$ & $\begin{array}{l}129.1 \\
(12.1)\end{array}$ & $\begin{array}{l}124.4 \\
(17.1)\end{array}$ & $\begin{array}{l}126.9 \\
(20.3)\end{array}$ & $\begin{array}{c}9.7 \\
\text { (4.7 to } 14.6)\end{array}$ & $\begin{array}{c}2.4 \\
(-1.1 \text { to } 5.9)\end{array}$ & $\begin{array}{c}1.2 \\
(-3.4 \text { to } 5.8)\end{array}$ \\
\hline \multicolumn{8}{|c|}{ Diastolic blood pressure, $\mathrm{mm} \mathrm{Hg}$} \\
\hline $\begin{array}{l}\text { Experiment day } \\
(08: 00-16: 00)\end{array}$ & $\begin{array}{c}77.7 \\
(10.5)\end{array}$ & $\begin{array}{l}78.0 \\
(7.5)\end{array}$ & $\begin{array}{l}76.3 \\
(9.2)\end{array}$ & $\begin{array}{l}75.8 \\
(9.7)\end{array}$ & $\begin{array}{c}1.1 \\
(-0.4 \text { to } 2.6)\end{array}$ & $\begin{array}{c}-0.8 \\
(-1.8 \text { to } 0.2)\end{array}$ & $\begin{array}{c}-1.4 \\
(-2.7 \text { to }-0.2)\end{array}$ \\
\hline $\begin{array}{l}24 \mathrm{~h}(16: 00-21: 00, \\
10: 00-16: 00)\end{array}$ & $\begin{array}{c}78.8 \\
(11.4)\end{array}$ & $\begin{array}{c}77.8 \\
(11.1)\end{array}$ & $\begin{array}{c}77.5 \\
(10.8)\end{array}$ & $\begin{array}{c}79.1 \\
(11.1)\end{array}$ & $\begin{array}{c}2.3 \\
(-0.3 \text { to } 4.8)\end{array}$ & $\begin{array}{c}-0.2 \\
(-2.0 \text { to } 1.5)\end{array}$ & $\begin{array}{c}1.0 \\
(-1.2 \text { to } 3.3)\end{array}$ \\
\hline $\begin{array}{l}24 \mathrm{~h} \text {-Evening } \\
(16: 00-21: 00)\end{array}$ & $\begin{array}{c}80.3 \\
(10.7)\end{array}$ & $\begin{array}{c}77.0 \\
(11.1)\end{array}$ & $\begin{array}{c}79.1 \\
(11.0)\end{array}$ & $\begin{array}{c}81.2 \\
(11.8)\end{array}$ & $\begin{array}{c}-0.5 \\
(-4.0 \text { to } 2.9)\end{array}$ & $\begin{array}{c}-0.4 \\
(-2.8 \text { to } 2.0)\end{array}$ & $\begin{array}{c}1.9 \\
(-1.1 \text { to } 4.9)\end{array}$ \\
\hline $\begin{array}{l}24 \mathrm{~h}-\text { Day after } \\
(10: 00-16: 00)\end{array}$ & $\begin{array}{c}77.3 \\
(11.8)\end{array}$ & $\begin{array}{c}78.6 \\
(11.2)\end{array}$ & $\begin{array}{c}75.9 \\
(10.5)\end{array}$ & $\begin{array}{l}76.7 \\
(9.7)\end{array}$ & $\begin{array}{c}5.0 \\
(1.5 \text { to } 8.5)\end{array}$ & $\begin{array}{c}0.2 \\
(-2.2 \text { to } 2.7)\end{array}$ & $\begin{array}{c}0.5 \\
(-2.6 \text { to } 3.7)\end{array}$ \\
\hline $\begin{array}{l}\text { Degree of difficulty } \\
\text { (RPE 0-10;0 = not } \\
\text { difficult) }\end{array}$ & $\begin{array}{c}0.9 \\
(1.8)\end{array}$ & $\begin{array}{c}0.7 \\
(1.3)\end{array}$ & $\begin{array}{l}0.8 \\
(1.5)\end{array}$ & $\begin{array}{c}0.2 \\
(0.6)\end{array}$ & $\begin{array}{c}-0.4 \\
(-1.1 \text { to } 0.4)\end{array}$ & $\begin{array}{c}-0.2 \\
(-0.7 \text { to } 0.3)\end{array}$ & $\begin{array}{c}-0.4 \\
(-1.0 \text { to } 0.2)\end{array}$ \\
\hline $\begin{array}{l}\text { Fatigue } \\
\text { (VAS 0-10; } 0=\text { not } \\
\text { fatigued) }\end{array}$ & $\begin{array}{l}2.1 \\
(2.1)\end{array}$ & $\begin{array}{l}2.1 \\
(2.4)\end{array}$ & $\begin{array}{c}1.7 \\
(2.3)\end{array}$ & $\begin{array}{c}1.0 \\
(1.5)\end{array}$ & $\begin{array}{c}-0.6 \\
(-1.2 \text { to }-0.1)\end{array}$ & $\begin{array}{c}-0.4 \\
(-0.7 \text { to }-0.1)\end{array}$ & $\begin{array}{c}-0.7 \\
(-1.1 \text { to }-0.3)\end{array}$ \\
\hline
\end{tabular}

Abbreviations: CI, confidence interval; RPE, ratings of perceived exertion; VAS, visual analogue scale. 


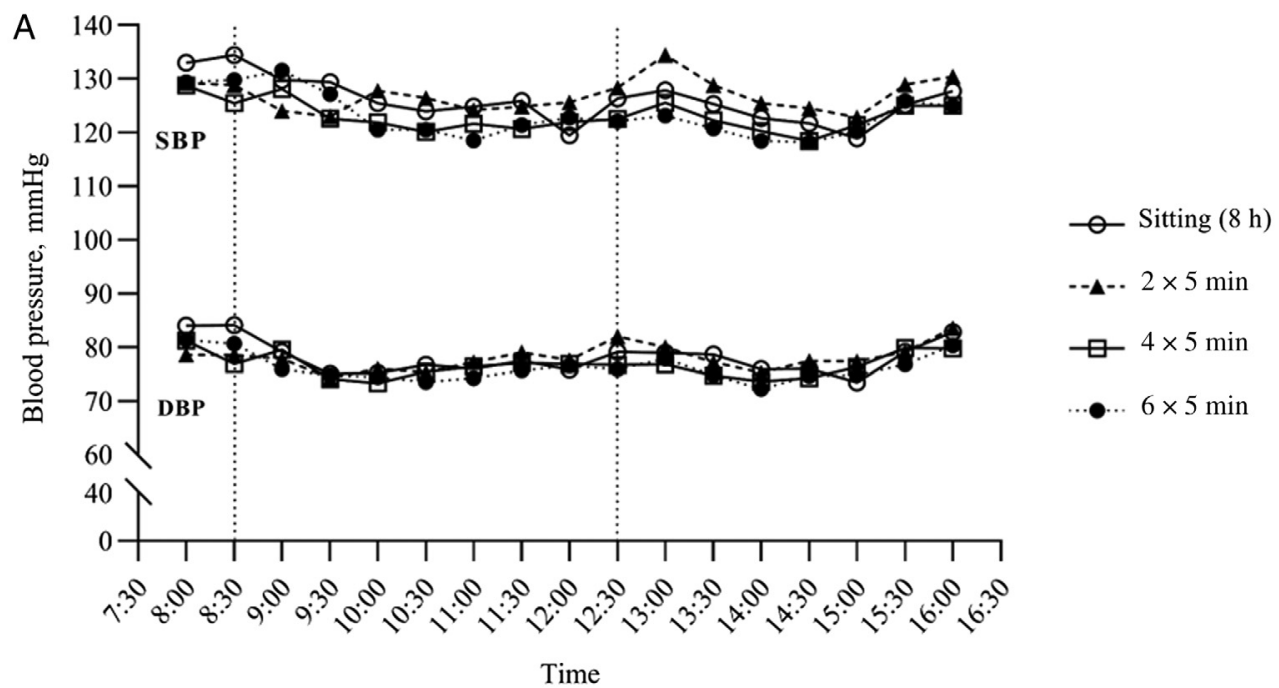

B

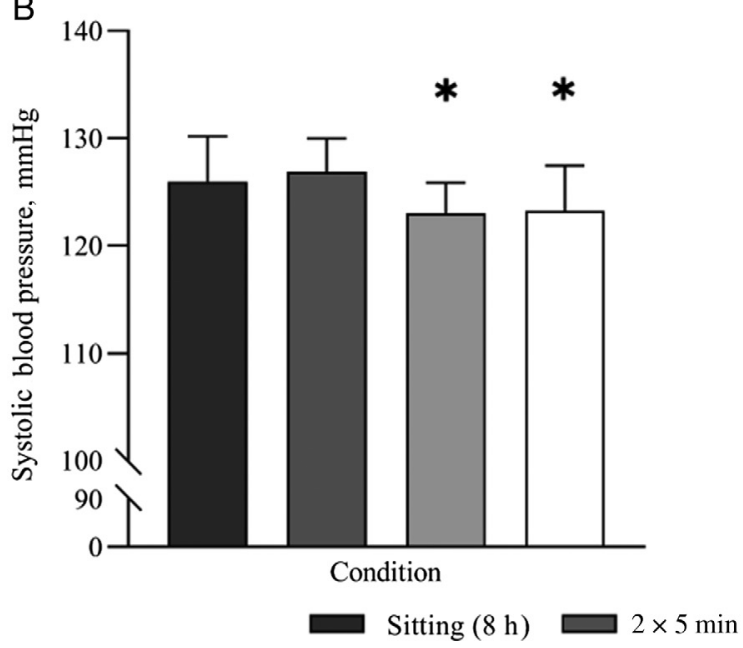

C

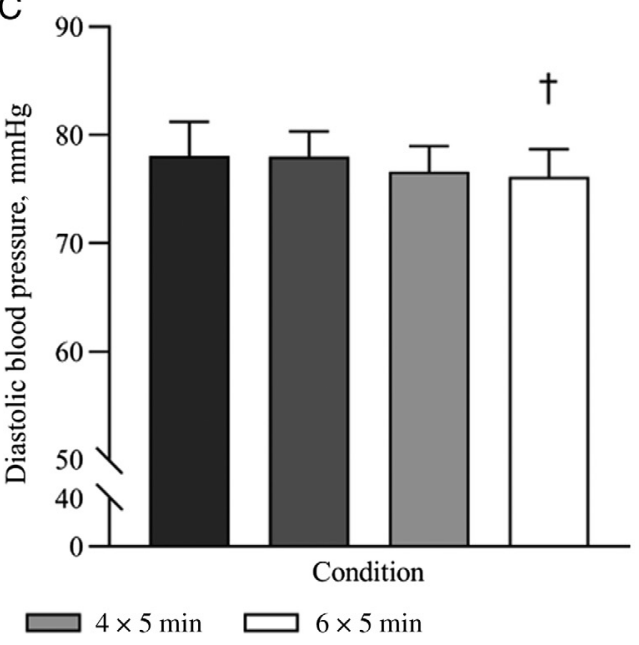

Figure 2 - Mean blood pressure responses for systolic and diastolic blood pressure across a day during each condition (A). (B, C) Represent baselineadjusted mean (SD) systolic and diastolic blood pressure during each condition, respectively. Vertical dashed lines (A) indicate breakfast (08:30) and lunch (12:30) meals. ${ }^{*} P<.001$ compared with prolonged sitting. ${ }^{\dagger} P<.05$ compared with prolonged sitting.

systolic blood pressure $(3.9 \mathrm{~mm} \mathrm{Hg}$; $95 \% \mathrm{CI}, 0.3$ to 7.6$)$ during the $2 \times 5$-minute condition compared with prolonged sitting. Diastolic blood pressure was also higher during both the $2 \times 5$-minute (2.5 $\mathrm{mm} \mathrm{Hg}$; $95 \% \mathrm{CI}, 0.1$ to 4.8$)$ and $4 \times 5$-minute $(1.9 \mathrm{~mm} \mathrm{Hg}$; $95 \% \mathrm{CI}, 0.2$ to 3.6$)$ conditions compared with prolonged sitting.

\section{Safety and Feasibility of STAND-EX Bouts}

Table 5 presents the pre- and post-STAND-EX heart rate and Borg ratings of perceived exertion for experimental conditions. During bouts of STAND-EX, the participants worked at a light intensity (average Borg score of $2=$ light intensity) with an average maximum heart rate of $53 \%(2 \times 5$ minutes, $56 \%$ heart rate maximum; $4 \times 5$ minutes, $53 \%$ heart rate maximum; $6 \times 5$ minutes, $52 \%$ heart rate maximum). The participants spent, on average, 300 (0.9) seconds on task during each experimental condition. There were no significant differences between conditions in self-reported degree of difficulty in completing the conditions $(P \geq .147)$. Selfreported fatigue at the end of the experimental condition was significantly lower for all experimental conditions $(2 \times 5 \mathrm{~min}$ :
$-0.6,95 \% \mathrm{CI},-1.2$ to $-0.1 ; 4 \times 5 \mathrm{~min}:-0.4,95 \% \mathrm{CI},-0.7$ to -0.1 , and $6 \times 5$ min: $-0.7,95 \% \mathrm{CI},-1.1$ to -0.3$)$ compared with prolonged sitting. Two participants were unable to complete marching on the spot during STAND-EX, so instead, they alternated between 20 seconds of mini squats and 20 seconds of calf raises.

Nine minor adverse events and 2 major adverse events were noted. The major adverse events were dizziness and nausea, not related to the trial, and resulted in 1 participant dropout $(n=1)$ and 1 testing day rescheduled $(n=1)$. The 9 minor adverse events included bruising (from the ambulatory blood pressure monitor cuff $[\mathrm{n}=3]$, the activPAL3 activity monitor $[\mathrm{n}=1]$, and at the cannulation site $[n=1])$, cramping $(n=1$; not due to STANDEX), delayed onset muscle soreness after experimental condition $1(\mathrm{n}=1)$, and nausea and stomachaches at the end of the control condition $(n=2)$. The protocol was strictly adhered to except for 1 participant receiving an additional serving of orange juice at the end of the sitting condition and 1 participant completing the first scheduled 5-minute break 30 minutes late during the $4 \times 5$ minute condition. 
Table 5 Mean (SD) of Conditions for Pre- and Post-STAND-EX Heart Rate and Pre- and Post-BORG RPE

\begin{tabular}{|c|c|c|c|c|c|c|}
\hline \multirow[b]{3}{*}{ Outcome } & \multicolumn{3}{|c|}{ Conditions } & & & \\
\hline & \multicolumn{3}{|c|}{ Pre-STAND-EX } & \multicolumn{3}{|c|}{ Post-STAND-EX } \\
\hline & $\begin{array}{c}2 \times 5 \text { min } \\
\text { condition } \\
(n=10)\end{array}$ & $\begin{array}{c}4 \times 5 \text { min } \\
\text { condition } \\
(n=29)\end{array}$ & $\begin{array}{c}6 \times 5 \text { min } \\
\text { condition } \\
(n=17)\end{array}$ & $\begin{array}{l}2 \times 5 \text { min } \\
\text { condition } \\
(n=10)\end{array}$ & $\begin{array}{c}4 \times 5 \text { min } \\
\text { condition } \\
(n=29)\end{array}$ & $\begin{array}{c}6 \times 5 \text { min } \\
\text { condition } \\
(n=17)\end{array}$ \\
\hline Heart rate, beats/min & $\begin{array}{l}67 \\
(9)\end{array}$ & $\begin{array}{l}65 \\
(9)\end{array}$ & $\begin{array}{c}64 \\
(10)\end{array}$ & $\begin{array}{c}86 \\
(15)\end{array}$ & $\begin{array}{c}81 \\
(13)\end{array}$ & $\begin{array}{c}79 \\
(12)\end{array}$ \\
\hline $\begin{array}{l}\text { BORG RPE } \\
\text { (RPE } 0-10 ; 0=\text { nothing } \\
\text { at all) }\end{array}$ & $\begin{array}{c}0.2 \\
(0.5)\end{array}$ & $\begin{array}{c}0.2 \\
(0.7)\end{array}$ & $\begin{array}{c}0.1 \\
(0.6)\end{array}$ & $\begin{array}{c}2.3 \\
(1.4)\end{array}$ & $\begin{array}{c}1.8 \\
(1.1)\end{array}$ & $\begin{array}{c}1.5 \\
(1.1)\end{array}$ \\
\hline
\end{tabular}

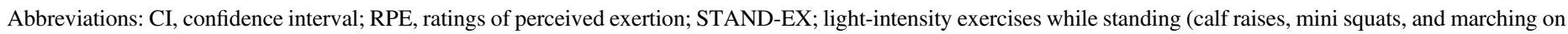
the spot).

\section{Discussion}

In this trial, interrupting 8 hours of sitting in stroke survivors with more frequent bouts of STAND-EX (4-6×5 min) was more effective at lowering systolic blood pressure than less frequent bouts $(2 \times 5 \mathrm{~min})$. Reductions in diastolic blood pressure were only found at the most frequent dose of STAND-EX $(6 \times 5 \mathrm{~min})$. Reductions in systolic and diastolic blood pressure were short term and did not appear to be sustained for 24-hour postexperimental conditions. However, missing data limit confidence in these results. Post hoc analyses suggest that stroke survivors on antihypertensive medication had greater reductions in systolic and diastolic blood pressure following more frequent bouts of STAND-EX. However, stroke survivors not on antihypertensive medication had a significant increase in blood pressure following STAND-EX bouts ( 2 and $4 \times 5 \mathrm{~min})$. All bouts of STAND-EX were shown to be safe and feasible.

Pharmacological strategies, in conjunction with lifestyle interventions, are cornerstones in the management of blood pressure and recurrent stroke risk. ${ }^{4}$ Small reductions of $\geq 2 \mathrm{~mm} \mathrm{Hg}$ in systolic and $\geq 2 \mathrm{~mm} \mathrm{Hg}$ in diastolic blood pressure are associated with $\mathrm{a} \geq 13 \%$ and $\geq 12 \%$ lower risk of stroke, respectively, in various populations..$^{4,29-31}$ Our data suggest that frequent, short bouts of light-intensity standing exercises may have an immediate effect in lowering blood pressure. Importantly, our findings found clinically significant reductions in blood pressure (systolic blood pressure, 2.1-3.7 $\mathrm{mm} \mathrm{Hg}$; diastolic blood pressure, $1.4-2.6 \mathrm{~mm} \mathrm{Hg}$ ) in stroke survivors with relatively well-controlled blood pressure (125/ $77 \mathrm{~mm} \mathrm{Hg}$ averaged across the control condition). Interestingly, the beneficial effects only occurred in stroke survivors on antihypertensive medication. This suggests that frequently breaking up prolonged sitting with STAND-EX, in conjunction with antihypertensive medication, may be a useful strategy to reduce recurrent stroke risk. However, the BUST-Stroke trial by English et al ${ }^{19}$ found reductions in systolic blood pressure in stroke survivors on and not on antihypertensive medication. Consequently, further research is warranted to understand the mechanism of antihypertensive medication in conjunction with light-intensity standingbased exercises.

The hypotensive effects of STAND-EX bouts on systolic blood pressure are consistent with previous findings in similar clinical populations, such as stroke survivors, ${ }^{19}$ those who are overweight/obese, ${ }^{17,20}$ people who are prehypertensive, ${ }^{32}$ and those with type 2 diabetes. ${ }^{16}$ In stroke survivors, the magnitude of effect was smaller in our study compared with the previous BUST-Stroke trial ${ }^{19}(-3.5 \mathrm{~mm} \mathrm{Hg}$ compared with -2.1 to $-2.3 \mathrm{~mm}$
$\mathrm{Hg}$, respectively). The greater effect in the BUST-Stroke trial could be due to the more frequent bouts of STAND-EX (every $30 \mathrm{~min}$ ), compared with the current trial (every 60 and $90 \mathrm{~min}$ ). We observed that more frequent bouts of STAND-EX were more effective at reducing systolic blood pressure $(1$ bout every $90 \mathrm{~min}=-2.1 \mathrm{~mm}$ $\mathrm{Hg}, 1$ bout every $60 \mathrm{~min}=-2.3 \mathrm{~mm} \mathrm{Hg}$ ) compared with less frequent bouts. This suggests that there may be a dose-response effect with regard to the frequency of activity bouts on systolic blood pressure. In addition, the benefits found on blood pressure following an accumulated 30 minutes $(6 \times 5 \mathrm{~min})$ of light-intensity standing exercises is consistent with the minimum 30 minutes per day recommendations suggested by committees and organizations for blood pressure management. ${ }^{33}$

Conversely, our results for diastolic blood pressure were different compared with BUST-Stroke. ${ }^{19}$ We found a significant reduction in diastolic blood pressure at the highest dose of STAND-EX $(6 \times 5 \mathrm{~min})$, whereas there were no between-condition differences in diastolic blood pressure in the BUST-Stroke trial. The discrepancies in trials could be due to the duration of STANDEX bouts ( $3 \mathrm{~min}$ vs $5 \mathrm{~min}$ ), with longer bouts showing more beneficial responses to diastolic blood pressure in stroke survivors. However, in those with type 2 diabetes $^{16}$ or with overweight or obesity, ${ }^{17}$ reductions have been found following 2- to 3-minute bouts of walking or simple resistance exercises every 20 to 30 minutes. Consequently, further research is warranted to determine the effects of more frequent activity bouts (every $30 \mathrm{~min}$ ) on systolic and diastolic blood pressure in stroke survivors.

In those who are overweight or obese ${ }^{20}$ or have prehypertension, ${ }^{32}$ interrupting prolonged sitting with regular activity has been shown to result in sustained reductions in blood pressure for up to 24 hours after experimental conditions. In overweight/obese individuals, accumulating 2.5 hours of cycling or standing reduced systolic blood pressure during experimental conditions $(8 \mathrm{~h} / \mathrm{d},-3$ to $-5 \mathrm{~mm} \mathrm{Hg}$ ) and for 3 hours ( -6 to $-13 \mathrm{~mm} \mathrm{Hg}$ ) following experimental conditions. ${ }^{20}$ Bhammar et $\mathrm{al}^{32}$ reported similar findings following $3 \times 10$ minute bouts of vigorous walking $\left(\mathrm{HR}_{\max }=\right.$ $75 \%-79 \%)$ in prehypertensive individuals during experimental conditions and the following 24 hours. In stroke survivors, we found 24-hour postexperimental systolic blood pressure increased following the lowest dose of STAND-EX $(2 \times 5 \mathrm{~min})$. The increase in 24-hour postexperimental systolic blood pressure in comparison with previous research could potentially be due to the lack of control placed on stimulants known to elevate blood pressure (caffeine) ${ }^{34}$ during the free-living condition. In addition, around one-third of the data was missing in the current trial, which could have further influenced the 24-hour postexperimental blood 
pressure results. While limits to missing data have been set previously, ${ }^{32}$ the current trial included all stroke survivors in analysis due to the small sample size $(n=29)$. Therefore, with the lack of control under free-living conditions and the larger proportion of missing data, the results should be interpreted with caution.

A key strength of this trial was the blinded collection of blood pressure every 30 minutes using the ambulatory blood pressure monitor. In addition, the free-living assessment of continuous 24hour blood pressure allowed for the assessment of postexperimental condition effects. The trial was not randomized and had a small sample size. Nonrandomization of groups reduces the internal validity of the findings. However, all experimental conditions were controlled to avoid confounding variables. This included controls placed on physical activity, diet, and external stimulus known to alter blood pressure. To reduce the potential of a stress-induced change in blood pressure, standardized meals and STAND-EX bouts were completed after blood pressure measures. However, the trial was only powered to detect between-condition differences in systolic blood pressure at the most frequent dose of STAND-EX and was not powered to detect clinically meaningful changes at other doses. In addition, no multiple adjustment testing was performed, increasing the risk of type I errors. The large amount of missing data during the 24-hour postexperimental conditions limits conclusions about continued intervention effects. Finally, the control condition was not conducted under free-living conditions. However, the control condition was largely reflective of realworld settings, as stroke survivors sit for more than 8 hours per day. ${ }^{11}$

Achieving an accumulated 30 minutes of standing-based lightintensity exercises in frequent, short bouts during 8 hours of prolonged sitting led to clinical, relevant reductions in systolic and diastolic blood pressure $(\sim 2 \mathrm{~mm} \mathrm{Hg})$ in stroke survivors. However, the reductions in systolic and diastolic blood pressure may be limited to people on antihypertensive medication in stroke survivors with controlled blood pressure. This indicates that standing-based light-intensity exercises in conjunction with pharmacological treatment may be more beneficial at reducing blood pressure than light-intensity standing exercises alone. Larger trials are warranted to confirm our results and to determine the feasibility and magnitude of effect under free-living conditions and the effects of blood pressure control in subgroups of stroke survivors (normotensive, prehypertensive, and hypertensive).

\section{Acknowledgments}

The authors would like to thank all stroke survivors who participated in the trial. The authors also acknowledge the help of the Hunter Stroke Research Volunteer Register in participant recruitment and Shaun Eslick and Rebecca McLoughlin, who helped with dietary assessments. This study is supported by a Hunter Medical Research Institute project grant (2016) and Heart Foundation Vanguard Grant (2017-no. 101727). Paul Mackie (PhD candidate) is supported by a University of Newcastle $\mathrm{PhD}$ scholarship, and Prof English is supported by a Heart Foundation Future Leader Fellowship (no. 101177). Professor David Dunstan is supported through a National Health and Medical Research Council Senior Research Fellowship (NHMRCAPP1078360) and the Victorian Government's Operational Infrastructure Support Program. Dr. Heidi Janssen is supported through an NSW Health EMC Clinical Research Fellowship (2017-2019) and the Hunter Medical Research Institute Women in Stroke Rehabilitation Research Fellowship (2019-2021). This trial was registered with the Australian New Zealand Clinical Trials Registry (ACTRN12617001517369).

\section{References}

1. Feigin VL, Roth GA, Naghavi M, et al. Global burden of stroke and risk factors in 188 countries, during 1990-2013: a systematic analysis for the Global Burden of Disease Study 2013. Lancet Neurol. 2016;15(9):913-924. PubMed ID: 27291521 doi:10.1016/S14744422(16)30073-4

2. O’Donnell MJ, Chin SL, Rangarajan S, et al. Global and regional effects of potentially modifiable risk factors associated with acute stroke in 32 countries (INTERSTROKE): a case-control study. Lancet. 2016;388(10046):761-775.

3. Mills KT, Bundy JD, Kelly TN, et al. Global disparities of hypertension prevalence and control: a systematic analysis of populationbased studies from 90 countries. Circulation. 2016;134(6):441-450. PubMed ID: 27502908 doi:10.1161/CIRCULATIONAHA.115. 018912

4. Pescatello LS, Franklin BA, Fagard R, Farquhar WB, Kelley GA, Ray CA. Exercise and hypertension. Med Sci Sports Exerc. 2004;36(3): 533-553. doi:10.1249/01.MSS.0000115224.88514.3A

5. Field MJ, Gebruers N, Shanmuga Sundaram T, Nicholson S, Mead G. Physical activity after stroke: a systematic review and meta-analysis. ISRN Stroke. 2013;2013:1-13.

6. Fini NA, Holland AE, Keating J, Simek J, Bernhardt J. How physically active are people following stroke? Systematic review and quantitative synthesis. Phys Ther. 2017;97(7):707-717. doi:10. 1093/ptj/pzx038

7. Butler EN, Evenson KR. Prevalence of physical activity and sedentary behavior among stroke survivors in the United States. Topics Stroke Rehabil. 2014;21(3):246-255. PubMed ID: 24985392 doi:10. 1310/tsr2103-246

8. Tieges Z, Mead G, Allerhand M, et al. Sedentary behavior in the first year after stroke: a longitudinal cohort study with objective measures. Archiv Phys Med Rehabil. 2015;96(1):15-23. PubMed ID: 25220942 doi:10.1016/j.apmr.2014.08.015

9. Paul L, Brewster S, Wyke S, et al. Physical activity profiles and sedentary behaviour in people following stroke: a cross-sectional study. Disabil Rehabil. 2016;38(4):362-367. PubMed ID: 25936730 doi:10.3109/09638288.2015.1041615

10. Hendrickx W, Riveros C, Askim T, et al. Identifying factors associated with sedentary time after stroke. Secondary analysis of pooled data from nine primary studies. Top Stroke Rehabil. 2019;26(5):327-334. PubMed ID: 31025908 doi:10.1080/ 10749357.2019.1601419

11. English C, Healy GN, Coates A, Lewis L, Olds T, Bernhardt J. Sitting and activity time in people with stroke. Phys Ther. 2016;96(2):193201. doi:10.2522/ptj.20140522

12. Thorp AA, Healy GN, Owen N, et al. Deleterious associations of sitting time and television viewing time with cardiometabolic risk biomarkers: Australian Diabetes, Obesity and Lifestyle (AusDiab) study 2004-2005. Diabetes Care. 2010;33(2):327-334. doi:10.2337/ dc09-0493

13. Lee PH, Wong FKY. The association between time spent in sedentary behaviors and blood pressure: a systematic review and meta-analysis. Sports Med. 2015;45(6):867-880. PubMed ID: 25749843 doi:10. 1007/s40279-015-0322-y

14. Mackie P, Weerasekara I, Crowfoot G, et al. What is the effect of interrupting prolonged sitting with frequent bouts of physical activity or standing on first or recurrent stroke risk factors? A scoping review. PLoS One. 2019;14(6):e0217981. PubMed ID: 31194799 doi:10. 1371/journal.pone.0217981

15. Chastin SF, Egerton T, Leask C, Stamatakis E. Meta-analysis of the relationship between breaks in sedentary behavior and cardiometabolic 
health. Obesity. 2015;23(9):1800-1810. PubMed ID: 26308477 doi:10.1002/oby. 21180

16. Dempsey PC, Sacre JW, Larsen RN, et al. Interrupting prolonged sitting with brief bouts of light walking or simple resistance activities reduces resting blood pressure and plasma noradrenaline in type 2 diabetes. J Hypertens. 2016;34(12):2376-2382. doi:10.1097/HJH. 0000000000001101.

17. Larsen RN, Kingwell BA, Sethi P, Cerin E, Owen N, Dunstan DW. Breaking up prolonged sitting reduces resting blood pressure in overweight/obese adults. Nutr Metabol Cardiovasc Dis. 2014;24(9): 976-982. PubMed ID: 24875670 doi:10.1016/j.numecd.2014.04.011

18. English C, Janssen H, Crowfoot $\mathrm{G}$, et al. Breaking up sitting time after stroke (BUST-stroke). Int J Stroke. 2018;13(9):921-931. PubMed ID: 30226448 doi:10.1177/1747493018801222

19. English C, Janssen H, Crowfoot G, et al. Frequent, short bouts of light-intensity exercises while standing decreases systolic blood pressure: Breaking Up Sitting Time after Stroke (BUST-Stroke) trial. Int J Stroke. 2018;13(9):932-940. PubMed ID: 30223728 doi:10. 1177/1747493018798535

20. Zeigler ZS, Mullane SL, Crespo NC, Buman MP, Gaesser GA. Effects of standing and light-intensity activity on ambulatory blood pressure. Med Sci Sports Exerc. 2016;48(2):175-181. doi:10.1249/ MSS.0000000000000754

21. Mackie P, Crowfoot G, Janssen H, et al. Breaking up sitting time after stroke-How much less sitting is needed to improve blood pressure after stroke (BUST-BP-Dose): protocol for a dose-finding study. Contemp Clin Trials Commun. 2019;13:100310. doi:10.1016/j. conctc. 2018.100310

22. Australian Government Department of Health. Australian type 2 diabetes risk assessment tool (AUSDRISK). https://www1.health. gov.au/internet/main/publishing.nsf/Content/chronic-diab-prev-aus/ \$File/austool5.pdf. Published 2016. Accessed May 2020.

23. Kasner SE, Cucchiara BL, McGarvey ML, Luciano JM, Liebeskind DS, Chalela JA. Modified National Institutes of Health Stroke Scale can be estimated from medical records. Stroke. 2003;34(2):568-570. PubMed ID: 12574577 doi:10.1161/01.STR.0000052630.11159.25.

24. Bamford J, Sandercock P, Dennis M, Warlow C, Burn J. Classification and natural history of clinically identifiable subtypes of cerebral infarction. Lancet. 1991;337(8756):1521-1526. doi:10.1016/01406736(91)93206-O
25. Smith ORF, Van Den Broek KC, Renkens M, Denollet J. Comparison of fatigue levels in patients with stroke and patients with end-stage heart failure: application of the fatigue assessment scale. J Am Geriatr Soc. 2008;56(10):1915-1919. PubMed ID: 18771452 doi:10.1111/j. 1532-5415.2008.01925.x

26. Winkler EAH, Bodicoat DH, Healy GN, et al. Identifying adults' valid waking wear time by automated estimation in activPAL data collected with a $24 \mathrm{~h}$ wear protocol. Physiol Meas. 2016;37(10): 1653-1668. doi:10.1088/0967-3334/37/10/1653

27. Schofield W. Predicting basal metabolic rate, new standards and review of previous work. Hum Nutr Clin Nutr. 1985;39:5-41. PubMed ID: 4044297

28. Borg GA. Psychophysical bases of perceived exertion. Med Sci Sports Exerc. 1982; 14(5):377-381.

29. Ettehad D, Emdin CA, Kiran A, et al. Blood pressure lowering for prevention of cardiovascular disease and death: a systematic review and meta-analysis. Lancet. 2016;387(10022):957-967. doi:10.1016/ S0140-6736(15)01225-8

30. Law MR, Morris JK, Wald NJ. Use of blood pressure lowering drugs in the prevention of cardiovascular disease: meta-analysis of 147 randomised trials in the context of expectations from prospective epidemiological studies. BMJ. 2009;338:b1665. PubMed ID: 19454737 doi:10.1136/bmj.b1665

31. Reboldi G, Gentile G, Angeli F, Ambrosio G, Mancia G, Verdecchia P. Effects of intensive blood pressure reduction on myocardial infarction and stroke in diabetes: a meta-analysis in 73,913 patients. J Hypertens. 2011;29(7):1253-1269. doi:10.1097/HJH.0b013e3283469976

32. Bhammar DM, Angadi SS, Gaesser GA. Effects of fractionized and continuous exercise on 24-h ambulatory blood pressure. Med Sci Sports Exerc. 2012;44(12):2270-2276. PubMed ID: 22776874 doi:10.1249/MSS.0b013e3182663117

33. Pescatello LS, MacDonald HV, Lamberti L, Johnson BT. Exercise for hypertension: a prescription update integrating existing recommendations with emerging research. Curr Hypertens Rep. 2015; 17(11):87-87. PubMed ID: 26423529 doi:10.1007/s11906-0150600-y

34. Farag NH, Whitsett TL, McKey BS, et al. Caffeine and blood pressure response: sex, age, and hormonal status. J Womens Health. 2010; 19(6):1171-1176. PubMed ID: 20500126 doi:10.1089/jwh.2009. 1664 